\title{
Allergy immunotherapy across the life cycle to promote active and healthy ageing: from research to policies
}

\author{
An AIRWAYS Integrated Care Pathways (ICPs) programme item (Action Plan B3 of the \\ European Innovation Partnership on active and healthy ageing) and the Global Alliance \\ against Chronic Respiratory Diseases (GARD), a World Health Organization GARD \\ research demonstration project
}

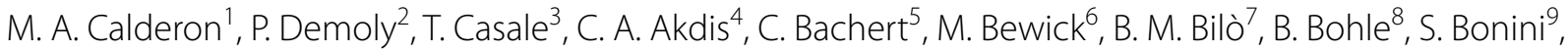 \\ A. Bush', D. P. Caimmi ${ }^{2}$, G. W. Canonica ${ }^{10}$, V. Cardona ${ }^{11}$, A. M. Chiriac ${ }^{12}$, L. Cox ${ }^{13}$, A. Custovic ${ }^{1}$, F. De Blay ${ }^{14}$, \\ P. Devillier ${ }^{15}$, A. Didier ${ }^{16}$, G. Di Lorenzo ${ }^{17}$, G. Du Toit ${ }^{18}$, S. R. Durham ${ }^{19}$, P. Eng ${ }^{20}$, A. Fiocchi ${ }^{21}$, A. T. Fox ${ }^{22}$, \\ R. Gerth van Wijk ${ }^{23}$, R. M. Gomez ${ }^{24}$, T. Haathela ${ }^{25}$, S. Halken ${ }^{26}$, P. W. Hellings ${ }^{27}$, L. Jacobsen ${ }^{28}$, J. Just ${ }^{29}$, \\ L. K. Tanno 30,31,32, J. Kleine-Tebbe ${ }^{33}$, L. Klimek ${ }^{34}$, E. F. Knol ${ }^{35}$, P. Kuna ${ }^{36}$, D. E. Larenas-Linnemann ${ }^{37,38,}$ \\ A. Linneberg ${ }^{39,40,41}$, M. Matricardi ${ }^{42}$, H. J. Malling ${ }^{43}$, R. Moesges ${ }^{44}$, J. Mullol ${ }^{45}$, A. Muraro ${ }^{46}$, N. Papadopoulos ${ }^{47}$, \\ G. Passalacqua ${ }^{48}$, E. Pastorello ${ }^{49}$, O. Pfaar ${ }^{50,51,52}$, D. Price ${ }^{53,54,55}$, P. Rodriguez del Rio ${ }^{56}$, R. Ruëff ${ }^{57}$, B. Samolinski ${ }^{58}$, \\ G. K. Scadding ${ }^{59,60}$, G. Senti ${ }^{61}$, M. H. Shamji6 ${ }^{62,63}$, A. Sheikh ${ }^{64}$, J. C. Sisul ${ }^{65}$, D. Sole ${ }^{66}$, G. J. Sturm ${ }^{67,68}$, A. Tabar ${ }^{69}$, \\ R. Van Ree ${ }^{70}$, M. T. Ventura ${ }^{71}$, C. Vidal ${ }^{72}$, E. M. Varga ${ }^{73}$, M. Worm ${ }^{74}$, T. Zuberbier ${ }^{74}$ and J. Bousquet ${ }^{31,75,76,77,78^{*}}$
}

\begin{abstract}
Allergic diseases often occur early in life and persist throughout life. This life-course perspective should be considered in allergen immunotherapy. In particular it is essential to understand whether this al treatment may be used in old age adults. The current paper was developed by a working group of AIRWAYS integrated care pathways for airways diseases, the model of chronic respiratory diseases of the European Innovation Partnership on active and healthy ageing (DG CONNECT and DG Santé). It considered (1) the political background, (2) the rationale for allergen immunotherapy across the life cycle, (3) the unmet needs for the treatment, in particular in preschool children and old age adults, (4) the strategic framework and the practical approach to synergize current initiatives in allergen immunotherapy, its mechanisms and the concept of active and healthy ageing.
\end{abstract}

Keywords: Allergen immunotherapy, EIP on AHA, AIRWAYS ICPs, Rhinitis, Asthma, Ageing

\section{Background}

Allergic diseases often occur early in life and persist throughout life. This life-course perspective should be considered in allergen immunotherapy (AIT). In

\footnotetext{
*Correspondence: jean.bousquet@orange.fr

${ }^{78}$ CHRU, 371 Avenue du Doyen Gaston Giraud, 34295 Montpellier Cedex

5, France

Full list of author information is available at the end of the article
}

particular it is essential to understand whether this immunological treatment may be used in old age adults.

The current paper was developed by a working group of AIRWAYS integrated care pathways (ICPs for airways diseases), the model of chronic respiratory diseases of the European Innovation Partnership on active and healthy ageing (DG CONNECT and DG Santé) to develop the concept of AIT across the life cycle and propose a strategic framework to be tested. 


\section{AIRWAYS integrated care pathways The political background}

Active and healthy ageing (AHA) is a major societal challenge, common to all populations. Ageing, together with gender, socio-economic and other forms of inequalities (https://www.equalityhumanrights.com/en/equality-act/ protected-characteristics), is an under-appreciated cause of poor health, which can have an adverse impact on economic development [1]. To tackle the burden of ageing in the European Union (EU), the European Commission launched the European Innovation Partnership (EIP) on AHA within its innovation policy [2]. The EIP on AHA is proposing a novel approach [2] that may be of great benefit to the economic consequences of the demographic changes in Poland. EIPs aim to enhance EU competitiveness and tackle societal challenges through research and innovation. They will address weaknesses in the EU research and innovation (e.g. under-investment, fragmentation and duplication), which complicate the discovery or exploitation of knowledge and may ultimately prevent the entry of innovations into the market place. EIP on AHA pursues a triple win for Europe:

- To enable EU citizens to lead healthy, active and independent lives while ageing.

- To improve the sustainability and efficiency of social and health care systems.

- To boost and improve the competitiveness of the markets for innovative products and services, responding to the ageing challenge at both $\mathrm{EU}$ and global level, thus creating new opportunities for businesses.

ICPs for chronic respiratory diseases (AIRWAYS ICPs) have been selected as a model for Action Plan B3 of the EIP on AHA Strategic Implementation Plan [3, 4]. The goals of AIRWAYS ICPs are to launch a collaboration to develop multi-sectoral care pathways for chronic respiratory diseases in European countries, regions and beyond in association with the World Health Organization (WHO) Global Alliance against chronic Respiratory Diseases (GARD research demonstration project) [5]. There are several ongoing actions among which:

- A synergy paper in press.

- A twinning for rhinitis in the elderly accepted yesterday by the EU.

- An App and a tablet for rhinitis and asthma deployed in 20 countries which received funding from private sources and the EU Development and Structural Funds [6-10].

- The scaling up strategy [11].
Prenatal and early-life events play a fundamental role in health and on the development of non-communicable diseases (NCDs) and AHA [12]. The Polish Presidency of the EU Council targeted chronic respiratory diseases in children to promote AHA [13]. It has been recognized that the prevention and early diagnosis and treatment of chronic respiratory diseases have a positive impact on child development and health-related quality of life and markedly contribute to an active and healthy childhood as well as AHA. Therefore, the development of new tools has been proposed for the early recognition and improvement of treatment for these conditions.

\section{Respiratory allergies across the life cycle}

IgE-mediated allergic diseases were defined by the World Allergy Organization [14] and include allergic rhinitis [15], allergic asthma [16], atopic dermatitis (AD) [17] and food allergy. However, IgE-mediated allergy is not always involved in the symptoms of these diseases [18-21] including non-allergic rhinitis, and non-allergic asthma.

Respiratory allergic diseases (asthma and rhinoconjunctivitis) are amongst the most common diseases worldwide [16]. They affect all age groups and rank first in Europe. The burden of these allergic diseases is substantial [22, 23] since they often impair social life as well as school and work performances [15, 24, 25]. Many patients are untreated or uncontrolled (despite treatment) [26], remain under-diagnosed and often do not receive adequate treatment. These factors all contribute to poor disease control.

Allergic diseases often start early in life and tend to persist across the life cycle, from infancy to the elderly. This is especially true with asthma or rhinitis, which may cause problems in individuals over 65 years of age [27]. Longitudinal birth cohort studies have shown sequential events leading to upper and lower respiratory allergies $[28,29]$. They start with weak sensitizations to a limited number of allergen components followed by strong and/ or new sensitizations to varying allergen sources depending on the region of the world [30-34]. However, in a large number of patients, sensitization does not change over time and is fully developed in pre-school children [29, 32, 35]. Moreover, the allergic march is uncommon [36]. The escalation of sensitization parallels with the clinical expression of the allergic disease. Genuine sensitizers (either for food- or inhalant-related allergens) tend to appear early in life, whereas specific IgE to pan-allergens appear later [37].

Cohort studies following participants into middle age have indicated that several factors, including childhood asthma, low or impaired lung function at an early age as well as atopy are risk factors for chronic obstructive pulmonary disease (COPD) $[38,39]$. In asthma, allergic 
sensitization was associated with worsening of healthrelated quality of life [40] in the elderly, with a high mortality risk due to under-diagnosis, under-treatment and comorbidity [41]. First-time exposure to an occupational allergen in any context (e.g. during apprenticeship) is indeed a period of increased risk of developing workrelated respiratory allergic diseases such as asthma and allergic rhinitis [42]. For example, occupational cleaners are associated with an increased risk of developing both asthma and self-reported COPD [43]. Established occupational asthma may persist in spite of complete allergen avoidance.

Over the past five decades, an "epidemic" of allergic diseases and asthma has been observed globally in children and adults [5]. The expected epidemic wave of asthma and rhinitis in elderly adults remains an insufficiently recognized problem [44-46]. In Europe, over 20\% of adults suffer from allergic rhinitis and over 5\% from asthma [15, 47]. These patients are now reaching the age of 65 and a new health challenge in elderly people will be to understand, detect and manage them. The importance of AIT in these patients needs to be better defined, tested and included in health policy making for the elderly [13].

Since we are entering an era of rapidly increasing elderly people, and considering that asthma and rhinitis usually commence during childhood or adulthood, both diseases represent an emerging public health concern in all age populations $[48,49]$.

\section{Rationale of allergy immunotherapy across the life cycle in AIRWAYS ICPs \\ Allergy and allergen immunotherapy scope}

Immunotherapy for IgE-mediated allergic diseases, referred to as AIT, has entered a new era [50-53]. It is characterized by: (1) thorough clinical development programmes leading to full registration and standardization of products; (2) better understanding of the functions of the immune system; (3) development of new products and routes to improve efficacy and safety; and (4) harmonized clinical practice parameters based on both evidence-based medicine and clinical experience. AIT includes both allergen- and non-allergen-containing therapeutics and is fully supported by the Polish Presidency of the Council of the EU [13] and the Finnish Allergy Plan [27, 54]. Although dosing is now established for some major allergens $[55,56]$, mixing of allergens is still a matter of debate and the selection of the allergen in some polysensitized patients may still be difficult.

\section{AIT induces immune tolerance}

The goals for AIT are to control the symptoms of patients who are unable to cope with their disease using optimal pharmacotherapy $[9,57,58]$. Ultimately, AIT aims to induce immune tolerance so that after its discontinuation, there are persistent therapeutic benefits [59, 60]. Whereas the early effects of AIT are probably related to basophil/mast cell down-regulation, AIT produces an early and transient inflammatory cell down-regulation and a transient to long-lasting $\mathrm{T}$ cell tolerance [61, 62]. This "tolerance" response is mainly mediated by IL-10, TGF- $\beta$ and other suppressive factors causing immune deviation towards a more balanced $\mathrm{T}$ regulatory cell response that leads to the observed suppression of cytokines from allergen-specific Th1 and Th2 cells [26, 63]. AIT also induces allergen-specific IL-10-producing memory $B$ regulatory cells, which seem to be responsible for specific IgG4 production. Furthermore, AIT is associated with the suppression of total IgE, allergen-specific $\mathrm{IgE}$, increases in allergen-specific blocking $\mathrm{IgG}_{4}$ antibodies [64, 65], a decrease in both tissue mast cells and eosinophil numbers [66] and the degree of activation.

\section{AIT efficacy and safety}

Clinical efficacy and safety of AIT for allergic asthma and allergic rhinoconjunctivitis for the most relevant allergen sources have been documented in well-powered randomized controlled trials, at least for specific products. Different systematic reviews and meta-analyses of studies in adults and children have confirmed efficacy for many relevant allergen sources [67-71]. However, some reviews were critical about AIT although certain criticisms were raised [72]. AIT improves disease-specific quality of life [73, 74]. Follow-up studies after the discontinuation of AIT have demonstrated a carry-over effect which can last for up to 12 years after its cessation [69, 75], but these studies are hampered by a high rate of drop outs and the effectiveness of these long-lasting effects needs more attention. AIT is thus a disease-modifying intervention (the only one currently available) with the potential of altering the allergic march [76, 77]. Double blind randomized controlled studies are currently ongoing in children allergic to grass pollens [78] and house dust mite to assess the potential prevention of asthma (EudraCT 2012-005678-76) (Table 1). It has been suggested that AIT is cost-effective although more information is needed $[53,79,80]$.

\section{Unmet needs}

1. Tolerance to AIT in very young children Considering that children born to atopic parents are at considerable increased risk of sensitization to common environmental allergens [81], it is important to establish the possible preventive role of AIT in reducing sensitization (primary prevention) to any allergens when given at infancy although the first results are inconclusive [82, 83] or difficult to interpret [84]. 


\section{Table 1 Types of biomarkers for AIT}

Identification and validation of biomarkers assessing the probability of response to treatment of AIT before it is initiated

Identification and validation of biomarkers assessing the safety of AIT before it is initiated

Identification and validation of biomarkers confirming the efficacy of AIT in patients receiving AIT (short and long term)

Identification and validation of biomarkers predicting the long-term effects of AIT before it is stopped

Identification and validation of biomarkers predicting the relapse of symptoms when AIT is stopped

2. When to start AIT in preschool children The demonstration of a progressive molecular-spreading process in allergic rhinitis [30] has provided the rationale for an early allergen-specific immunological intervention [85]. In this respect, studies on a 'secondary allergen immuno-prophylaxis' may be targeted to children who are already sensitized to airborne allergens but still asymptomatic. The ongoing allergic immune response is likely to be more susceptible of being suppressed in the first, weaker, pre-clinical monomolecular stages, rather than in the polymolecular clinical stages. It is also plausible that AIT will have a greater efficacy if started immediately after the disease onset rather than, as usual, years later. This concept of 'early AIT' should be tested in properly designed prospective trials [85].

The results of the EU programme on Mechanisms of the Development of ALLergy (MeDALL) have improved the stratification of allergic preschool children for diagnosis, prognosis and AIT [28, 29]. Multi-morbidity, co-existing allergic diseases (such as atopic eczema, allergic rhinitis and asthma) [86] and/or IgE polysensitisation are markers of clinical disease and disease persistence. For the first time ever, MeDALL is proposing a scientific answer for the initiation of AIT in pre-school children as it has found that the vast majority of those with multimorbidities will have persistent allergic conditions $[33,87]$. This finding has the potential to guide physicians to consider starting AIT early in life and this might lead to a greater expected efficacy to modify the course of allergy. Moreover, allergy with polysensitisation to birch pollen [32], cat or dog [31], or peanut (Asarnoj, in preparation) at age four can predict the onset and/or persistence of rhinitis and asthma at 16 years. The MeDALL results have been confirmed in patient cohorts $[88,89]$. It is therefore suggested that preschool children with asthma and rhinitis already sensitized may be considered as candidates for AIT.
3. Clinical tools to evaluate AIT There is a high degree of clinical and methodological heterogeneity among the endpoints in clinical studies on AIT, for both SCIT (sub-cutaleous AIT) and SLIT (sublingual AIT). At present, there are no commonly accepted standards for defining the optimal outcome parameters to be used for both primary and secondary endpoints [90]. A Task Force of the European Academy of Allergy and Clinical Immunology (EAACI) Immunotherapy Interest Group evaluated the currently used outcome parameters in different RCTs and provided recommendations for the optimal endpoints in future AIT trials for allergic rhinoconjunctivitis. Recommendations for nine domains of clinical outcome measures were made and recommended a homogeneous combined symptom and medication score (CSMS) was recommended as a primary outcome [90]. New ICT-based technology is likely to considerably change patient reported outcomes (PROs) for AIT during clinical trials and daily practice $[6,7,91]$. PROs should be adapted to the age groups. Caregivers are less able than children to accurately assess response to treatment with available tools. A simple pediatric-specific tool to assess efficacy in allergic rhinitis trials in children is needed [92-95]. In older adults, very few studies have investigated PROs, but visual analogue scales appear to be of interest $[92,96$, 97].

4. Stratification of patients allowing precision medicine Precision medicine is a medical model aiming to deliver customized healthcare-with medical decisions, practices, and/or products tailored to the individual patient. AIT has a unique immunological rationale, since the approach is tailored to the specific IgE sensitization of an individual. It modifies the natural course of the disease as it aims to have a persistent efficacy after completion of treatment. In this perspective, AIT can be considered a prototype of precision medicine [98]. Biomarkers associated with e-health, combined with a clinical decision support system (CDSS), might change the scope of AIT.

5. Relevant immune mechanisms Several immune changes have been associated with AIT. However, the most relevant immune mechanisms leading to clinical successful AIT have not yet been identified. This might be due to different administrations of AIT, different allergens, different products, etc. Deciphering the relevant immune mechanisms is of the upmost importance to further improve treatment protocols, finding relevant biomarkers, and to improve the composition of AIT products.

6. Biomarkers Biomarkers in allergic diseases and asthma are of great importance and a large body of 
research has been initiated [98]. The identification of biomarkers is based on systems biology approaches combining transcriptomics, proteomics, epigenetics and metabolomics in large patient cohorts. Two EUfunded projects are currently ongoing: U-BIOPRED (IMI) in severe asthma [99-101] and MeDALL (FP7) in allergy $[28,29]$. These projects will help to identify biomarkers for AIT efficacy [102-104] and safety, and to better establish the personalized medicine approach [105]. The following issues should be addressed (Table 1):

7. IgE sensitization profiles Combinatorial analysis has shown that the IgE sensitization profiles to grass pollen in children with hay fever are very heterogeneous at the molecular level [34, 106, 107]. This high heterogeneity is important in a scenario of precision medicine. Accordingly, a classification of different categories of match and mismatch between the molecular profiles of IgE sensitization and the molecular profile of an AIT preparation has been illustrated [106]. Studies are needed to evaluate the putative impact of matched or mismatched IgE between the sensitization profile and the molecular composition of the AIT preparation used in the individual patient. Moreover, recent studies in over 1300 Italian children with seasonal allergic rhinitis have shown the importance of component-resolved diagnosis (CRD) on the prescription of AIT against pollens [108]. Molecular diagnosis with marker allergens is nowadays a promising diagnostic step in poly-sensitized individuals and it is essential to distinguish the primary sensitizers and "true" reactions from cross-reactivity caused by pan-allergens.

AIT efficacy may be predicted by the IgE profile [102, 109, 110], but more data are needed.

8. AIT in older adults The role of AIT for the treatment of allergic diseases in old age should be considered. The research agenda must include not only well powered randomized controlled trials in this age group but also specific research on the immune response, time of onset of allergic disease (since childhood, adult life or late-onset in life), comorbidities, safety and cost-benefits of AIT.

9. AIT in pregnancy Allergic diseases such as asthma and allergic rhinitis constitute a significant burden among women of childbearing age and those who are pregnant. The continuation of AIT during pregnancy appears safe [111]. Available studies do not however show a convincing reduction in the development of atopy in offspring from the administration of AIT during pregnancy [111].

10. AIT for skin allergy A Cochrane review found limited evidence that AIT may be effective for people with atopic eczema [112]. The treatments used in these trials were not associated with an increased risk of local or systemic reactions. Future studies should use high quality allergen formulations with a proven track record in other allergic conditions and should include PROs as key outcome measures.

11. SCIT versus SLIT Direct head-to-head comparisons of subcutaneous AIT (SCIT) versus sublingual AIT (SLIT; tablets or drops) are limited [113] and have generated contradictory results [114]. Similarly, indirect comparisons are inconsistent. This is perhaps due to the lack of standardization of clinical outcomes measured, dosages, heterogeneous compositions, schedules and duration of treatment [67]. There are very few SCIT studies that meet the CONSORT criteria for publication and most are not ITT analyses $[115,116]$. Moreover, efficacy and safety have been shown only for some SLIT and SCIT products. Comparisons should also be made between products [117]. For some allergen sources and age groups, effective SLIT or SCIT doses have not been established [69].

12. AIT in polysensitized individuals Although AIT has proven efficacy in large, robust clinical trials in primarily polysensitized patients [55, 69], more work is required to determine whether single-allergen source and multi-allergen source AIT also produce distinct immune and clinical responses in monosensitized and polysensitized patients [118]. The currently available literature suggests that when the clinically relevant allergen has been identified, AIT is effective also in polysensitized patients [118].

13. Ideal schedule for sublingual AIT For some allergen extract preparations, efficacy (SLIT with pollen) has been shown with a pre-coseasonal administration schedule, as opposed to other extracts for which the year-round perennial schedule is recommended. This has implications for the cost-benefit analysis as well as for adherence. Until direct comparative studies between dosing are conducted, it is speculative as to which schedule adherence might ultimately be enhanced.

14. Duration of AIT International harmonisation on the criteria used to determine the duration of AIT is necessary. Adherence to treatment, route of administration, cost, allergen source, patient's comorbidities and polysensitisation are all factors that should be considered as well as the age of onset of AIT. It is usually recommended to perform AIT for a duration of 3 years, but data are insufficient.

15. Cost-effectiveness A health technology assessment study funded by the UK National Institute for Health Research Health Technology Assessment (NIHR 
HTA) programme concluded that a benefit from both SCIT and SLIT compared with placebo has been consistently demonstrated. However, the extent of this effectiveness in terms of clinical benefit is unclear. Both SCIT and SLIT may be cost-effective compared with AIT from around 6 years (threshold of $£ 20,000-30,000$ per QALY) [80]. In a US study based on Florida Medicaid data on allergic rhinitis patients from poverty environments, the cut-even point for SCIT was already reached at 3 months [119]. The results of this study are restricted to the US model and the population treated. Further research is urgently needed to establish the comparative effectiveness of SCIT compared with SLIT and to provide more robust cost-effectiveness estimates $[71,80]$. Although it is not accepted by regulators yet, cost-effectiveness might be best shown in more real-life trial designs.

16. Novel forms of AIT Recombinant allergens [74, 120, 121] or the chemical and molecular modification of allergens and the use of different routes of administration of AIT should aim to facilitate its use for a wider scope of allergic diseases. However, these new options should be assessed in the context of the patient's convenience and adherence to treatment, long-term efficacy, disease-modifying effects and cost-benefits. Biologics added to AIT may be effective for some (anti-IgE [122-124]) but not all targets (anti-IL-4 [125]). In this case, an economic evaluation is needed to stratify the patients.

\section{Proposal to integrate AIT in AIRWAYS ICPs Strategic framework}

Integration and dissemination of international and national clinical practice guidelines are part of the process of ICPs. ICPs differ from practice guidelines as they are utilized by a multidisciplinary team and focus on the quality and coordination of care. Clinicians are free to exercise their own professional judgment as appropriate. An ICP is intended to act as a guide to treatment for the single patient. Any alteration to the practice identified within the ICP algorithm should be noted as a variance. Variance analysis can be used to amend the ICP itself if, for a group of patients, the practice consistently differs from the pathway.

ICPs form all or part of the clinical record, document the care given, and facilitate the evaluation of outcomes for continuous quality improvement. They should empower patients and their health and social care givers.

\section{Objectives}

The aims of AIRWAYS ICPs are to:
- Better understand the role of AIT across the life cycle, particularly in preschool children (prevention and treatment) and in the elderly.

- Increase the awareness of the impact of AIT across the life cycle to promote AHA.

- Better stratify patients who benefit the most from AIT in all age groups.

- Launch a collaboration to develop care pathways for chronic respiratory allergic diseases integrating AIT in European countries and regions in the frame of AIRWAYS ICPs.

- Follow and implement actions and plans suggested by this integrated collaboration.

- Provide evidence for regulatory decisions.

- Propose new policies in the EU. AIRWAYS ICPs and AIT to be incorporated in Action Plan B3 of the EIP on AHA.

- Follow and implement actions and plans suggested by this integrated collaboration, which are to be endorsed by national health authorities.

\section{Approach}

This project aims to synergize current initiatives in AIT, allergic diseases and healthy ageing, as part of the AIRWAYS ICPs programme.

A multi-sectoral approach is proposed. It will include all targeted groups such as (1) the general population (patients, parents, teachers, media, patient's associations), (2) primary care (general practitioners and general pediatricians, pharmacists, nurses) and (3) secondary care (allergists, organ and other allergy specialists including pediatrics, ENT, internal medicine, dermatology, respiratory, clinical immunologists, and patient associations).

Partners will include (1) relevant academic consortia (MeDALL, GA ${ }^{2}$ LEN, ARIA, PRACTALL), (2) relevant academic societies (both national and international), (3) manufacturers of allergy diagnostics and allergen preparations.

A stratification of patients across the life cycle using novel biomarkers, e-health and CDSS.

The integration of modern e-health tools should be promoted. Indeed, the use of electronic information and communications technologies in health is rising rapidly in the developing world, offering essential improvements in the management of respiratory allergies. This technology will allow better disease control and monitoring, promoting AIT compliance. These will include: (1) the Sentinel Network of GA ${ }^{2} L E N$ and MACVIA-LR, (2) the MASK model of MACVIA-LR, including novel CDSS [7, $126]$ and (3) the currently available applications of certain investigators and pharmaceutical companies. 
A stepwise framework is favoured. The AIRWAYS ICPs group will collect data, make proposals and then disseminate and evaluate actions.

Step 1-Data collection We are aiming to create a portfolio providing all available current published data on the subject. As an example, the most recent documents provided by EAACI (AIT guidelines and consensus reports), ARIA (rhinitis and asthma guidelines), and WAO (SLIT guidelines) will be included and deposited in the EIP on AHA repository.

Step 2-Proposals and actions We will summarize and select the best feasible proposals to integrate AIT in AIRWAYS ICP across the EU. As an example, the best windows of intervention for AIT in children and all possible interventions later in life will be scrutinized.

Step 3-Dissemination and follow-up Use of the proposals will be promoted as much as possible and surveyed. As an example, a module will be created for presentations at national and EU meetings, as well as for e-learning.

Step 4-Changes in policies Policies for senior citizens in countries should reflect the epidemiologic wave of the still unrecognized allergic diseases in the elderly. Novel approaches in health systems and reimbursement policies are needed for AIT in well-stratified patients using modern technologies. The effectiveness, cost-effectiveness and safety of such policies will need to be established.

\begin{abstract}
Abbreviations
AHA: active and healthy ageing; AIRWAYS ICPs: integrated care pathways for airway diseases; ARIA: allergic rhinitis and its impact on asthma; AIT: allergen immunotherapy; CDSS: clinical decision support system; CONSORT: consolidated standards of reporting trials; COPD: chronic obstructive pulmonary disease; CRD: chronic respiratory diseases; DG: Directorate General; EIP on AHA: European Innovation Partnership on active and healthy ageing; EU: European Union; GA² LEN: Global Allergy and Asthma European Network (FP6); GARD: WHO global alliance against chronic respiratory diseases; ICP: integrated care pathway; IL: interleukin; MACVIA-LR: contre les MAladies Chroniques pour un Vleillissement Actif (fighting chronic diseases for active and healthy ageing); MASK: MACVIA-ARIA Sentinel NetworK; MeDALL: Mechanisms of the Development of ALLergy (FP7); MOH: Ministry of Health; NCD: non-communicable disease; PRACTALL: PRACTicing ALLergology; PRO: patient reported outcome; RCT: randomized control trial; SCIT: subcutaneous immunotherapy; SLIT: sublingual immunotherapy; Th:T helper cell; U-BIOPRED: Unbiased BIOmarkers in PREDiction of respiratory disease outcomes; WHO: World Health Organization.
\end{abstract}

\section{Authors' contributions}

JB drafted the paper. All authors are members of the ARIA and/or MACVIAARIA working groups and read and commented the paper. All authors read and approved the final manuscript.

\footnotetext{
Author details

${ }^{1}$ National Heart and Lung Institute, Royal Brompton Hospital NHS, Imperial College London, London, UK. ${ }^{2}$ Unité d'allergologie, Département de Pneumologie et AddictologieHôpital Arnaud de Villeneuve, CHRU de Montpellier, Sorbonne Universités, UPMC Paris 06, UMR-S 1136, IPLESP, Equipe EPAR, 75013 Paris, France. ${ }^{3}$ University of South Florida Morsani College of Medicine, Tampa, FL, USA. ${ }^{4}$ Christine Kühne Center for Allergy Research
}

and Education (CK-CARE), Swiss Institute of Allergy and Asthma Research (SIAF)University of Zurich, Davos, Switzerland. ${ }^{5}$ Upper Airways Research Laboratory (URL), ENT Department, University Hospital Ghent, Ghent, Belgium. ${ }^{6} \mathrm{iQ} 4 \mathrm{U}$ consultants Ltd, London, UK. ${ }^{7}$ Allergy Unit, Department of Internal Medicine, University Hosp Ospedali Riuniti, Ancona, Italy. ${ }^{8}$ Department of Pathophysiology and Allergy Research, Center of Pathophysiology, Infectiology and Immunology, Medical University of Vienna, Vienna, Austria. ${ }^{9}$ Second University of Naples and IFT-CNR, Rome, Italy. ${ }^{10}$ Allergy and Respiratory Diseases Clinic, DIMI, University of Genoa, IRCCS AOU San Martino-IST, Genoa, Italy. ${ }^{11}$ Allergy Section, Department of Internal Medicine, Hospital Universitari Vall d'Hebron, Barcelona, Spain. ${ }^{12}$ Division of Allergy, Hôpital Arnaud de Villeneuve, Department of Pulmonology, University Hospital of Montpellier, Montpellier - UPMC Univ Paris 06, UMRS 1136, Equipe - EPAR - IPLESP, Sorbonne Universités, Paris, France. ${ }^{13}$ Nova Southeastern University, Ft. Lauderdale, FL, USA. ${ }^{14}$ Allergy Division, Chest Disease Department, University Hospital of Strasbourg, Strasbourg, France. ${ }^{15}$ University Versailles Saint-Quentin and Clinical Pharmacology Unit, UPRES EA 220, Department of Airway Diseases, Foch Hospital, Suresnes, France. ${ }^{16}$ Respiratory Diseases Department, Rangueil-Larrey Hospital, Toulouse, France. ${ }^{17}$ Dipartimento BioMedico di Medicina Interna e Specialistica (Di.Bi.M.I.S), University of Palermo, Palermo, Italy. ${ }^{18}$ Guy's and St. Thomas' NHS Trust, Kings College, London, UK. ${ }^{19}$ Allergy and Clinical Immunology Section, National Heart and Lung Institute, Imperial College London, London, UK. ${ }^{20}$ Department of Pediatric Pulmonology and Allergy, Children's Hospital, Aarau, Switzerland. ${ }^{21}$ Division of Allergy, Department of Pediatrics, Bambino Gesù Pediatric Hospital, Vatican City, Rome, Italy. ${ }^{22}$ King's College London Allergy Academy, London, UK. ${ }^{23}$ Section of Allergology, Department of Internal Medicine, Erasmus Medical Center, Building Rochussenstraat, Rotterdam, The Netherlands. ${ }^{24}$ Unidad Alergia and Asma, Hospital San Bernardo, Salta, Argentina. ${ }^{25}$ Skin and Allergy Hospital, Helsinki University Hospital, Helsinki, Finland. ${ }^{26}$ Hans Christian Andersen Children's Hospital, Odense University Hospital, Odense, Denmark. ${ }^{27}$ Clinical Department of Otorhinolaryngology, Head and Neck Surgery, University Hospitals Leuven, KU Leuven, Louvain, Belgium. ${ }^{28}$ Allergy Learning and Consulting, Secretary Immunotherapy Interest Group EAACI, Copenhagen, Denmark. ${ }^{29}$ Allergology Department, Centre de l'Asthme et des Allergies, Hôpital d'Enfants Armand-Trousseau, INSERM, UMR_S 1136, Sorbonne Universités, UPMC Univ Paris, Institut Pierre Louis d'Epidémiologie et de Santé Publique, Equipe EPAR, Paris, France.

${ }^{30}$ Hospital Sírio Libanês, São Paulo, Brazil. ${ }^{31}$ University Hospital of Montpellier, Montpellier, France. ${ }^{32}$ UPMC Paris 06, UMR-S 1136, IPLESP, Equipe EPAR, Sorbonne Universités, Paris, France. ${ }^{33}$ Allergy and Asthma Center Westend, Outpatient Clinic and Clinical Research Center, Ackermann, Hanf, \& Kleine-Tebbe, Berlin, Germany. ${ }^{34}$ Center for Rhinology and Allergology, German Society for Otorhinolaryngology HNS, Wiesbaden, Germany. ${ }^{35}$ Departments of Immunology and Dermatology/Allergology, University Medical Center Utrecht, Heidelberglaan, Utrecht, The Netherlands. ${ }^{36}$ Medical University of Lodz, Lodz, Poland. ${ }^{37}$ ARIA, Mexico, DF, Mexico. ${ }^{38}$ AAAAI, Hospital Médica Sur, Mexico, DF, Mexico. ${ }^{39}$ Research Centre for Prevention and Health, The Capital Region of Denmark, Copenhagen, Denmark. ${ }^{40}$ Department of Clinical Experimental Research, Rigshospitalet, Copenhagen, Denmark. ${ }^{41}$ Department of Clinical Medicine, Faculty of Health and Medical Sciences, University of Copenhagen, Copenhagen, Denmark. ${ }^{42}$ Pediatric Pneumology and Immunology, Charité Medical University, Berlin, Germany. ${ }^{43}$ Danish Allergy Centre, Allergy Clinic, Gentofte University Hospital, Hellerup, Denmark. ${ }^{44}$ IMSIE, Klinikum der Universität zu Köln A. ö. R., Cologne, Germany. ${ }^{45}$ Unitat de Rinologia i Clínica de l'Olfacte, ENT Department, Hospital Clínic, Clinical and Experimental Respiratory Immunoallergy, IDIBAPS, CIBERES, Barcelona, Catalonia, Spain. ${ }^{46}$ Department of Women and Child Health, Food Allergy Referral Centre Veneto Region, Padua General University Hospital, Padua, Italy. ${ }^{47}$ Allergy Unit, 2nd Pediatric Clinic, University of Athens, Athens, Greece.

${ }^{48}$ Allergy and Respiratory Diseases, IRCCS San Martino-IST, Univesity of Genoa, Genoa, Italy. ${ }^{49}$ ASST Grande Ospedale Metropolitano Niguarda, P.zza Ospedale Maggiore, Milan, Italy. ${ }^{50}$ Department of Otorhinolaryngology, Head and Neck Surgery, Universitätsmedizin Mannheim, Mannheim, Germany. ${ }^{51}$ Medical Faculty Mannheim, Heidelberg University, Heidelberg, Germany. ${ }^{52}$ Center for Rhinology and Allergology, Wiesbaden, Germany. ${ }^{53}$ Division of Applied Health Sciences, Primary Care Respiratory Medicine, Academic Primary Care, University of Aberdeen, Aberdeen, Scotland, UK. ${ }^{54}$ Research in Real Life (RiRL), Oakington, Cambridge, UK. ${ }^{55}$ Optimum Patient Care Ltd, Singapore, Singapore. ${ }^{56}$ Allergy Section, Hospital Infantil Universitario Niño Jesús, Madrid, Spain. ${ }^{57}$ Department of Dermatology and Allergology, Ludwig-Maximillian 
University, Munich, Germany. ${ }^{58}$ Department of Prevention of Environmental Hazards and Allergology, Medical University of Warsaw, Warsaw, Poland. ${ }^{59}$ Royal National Throat, Nose and Ear Hospital, London, UK. ${ }^{60}$ University College London, London, UK. ${ }^{61}$ Clinical Trials Center, University Hospital of Zurich, Zurich, Switzerland. ${ }^{62}$ Immunomodulation and Tolerance Group, Allergy and Clinical Immunology, Inflammation, Repair and Development Section, National Heart and Lung Institute, Faculty of Medicine, Imperial College London, London, UK. ${ }^{63} \mathrm{MRC}$ and Asthma UK Centre in Allergic Mechanisms of Asthma, London, UK. ${ }^{64}$ Asthma UK Centre for Applied Research, Centre for Medical Informatics, Usher Institute of Population Health Sciences and Informatics, The University of Edinburgh, Teviot Place, Edinburgh EH8 9AG, UK. ${ }^{65}$ SLAAl, Asuncion, Paraguay. ${ }^{66}$ Programa de Pòs-Graduação em Pediatria e Ciências Aplicadas à Pediatria, Departamento de Pediatria EPM, UNIFESP, São Paulo, Brazil. ${ }^{67}$ Department of Dermatology and Venerology, Medical University of Graz, Graz, Austria. ${ }^{68}$ Allergy Outpatient Clinic Reumannplatz, Vienna, Austria. ${ }^{69}$ Servicio de Alergologia, Complejo Hospitalario de Navarra, Pamplona, Spain. ${ }^{70}$ Departments of Experimental Immunology and Otorhinolaryngology, Academic Medical Center, University of Amsterdam, Amsterdam, The Netherlands. ${ }^{71}$ Unit of Geriatric Immunoallergology, Interdisciplinary Department of Medicine, University of Bari Medical School, Bari, Italy. ${ }^{72}$ Allergy Department, Complejo Hospitalario Universitario de Santiago de Compostela, Santiago de Compostela, Spain. ${ }^{73}$ Respiratory and Allergic Disease Division, Department of Paediatrics, Medical University of Graz, Graz, Austria. ${ }^{74}$ Allergie-Centrum-Charité, Klinik für Dermatologie, Venerologie und Allergologie, Charité-Universitätsmedizin Berlin, Berlin, Germany. ${ }^{75}$ Contre les MAladies Chroniques pour un Vleillissement Actif en Languedoc-Roussillon, European Innovation Partnership on Active and Healthy Ageing Reference Site, Paris, France. ${ }^{76}$ INSERM, VIMA, U1 168 , Ageing and Chronic Diseases, Epidemiological and Public Health Approaches, Paris, France. ${ }^{77}$ UVSQ, UMR-S 1168, Université Versailles St-Quentin-en-Yvelines, Versailles Cedex, France. ${ }^{78}$ CHRU, 371 Avenue du Doyen Gaston Giraud, 34295 Montpellier Cedex 5, France.

\section{Acknowledgements}

None.

\section{Competing interests}

The authors declare that they have no competing interests.

\section{Funding}

European Innovation Partnership on Active and Healthy Ageing Reference Site MACVIA-France, European Structural and Development Funds of Region Languedoc Roussillon.

Received: 25 September 2016 Accepted: 2 November 2016 Published online: 23 November 2016

\section{References}

1. Rechel B, Grundy E, Robine JM, Cylus J, Mackenbach JP, Knai C, et al. Ageing in the European Union. Lancet. 2013;381(9874):1312-22.

2. Bousquet J, Michel J, Standberg T, Crooks G, lakovidis I, Gomez M. The European Innovation Partnership on Active and Healthy Ageing: the European geriatric medicine introduces the EIP on AHA column. Eur Geriatr Med. 2014;5(6):361-2.

3. Bousquet J, Barbara C, Bateman E, Bel E, Bewick M, Chavannes NH, et al. AIRWAYS-ICPS (European Innovation Partnership on Active and Healthy Ageing) from concept to implementation. Eur Respir J. 2016;47(4):1028-33.

4. Bousquet J, Addis A, Adcock I, Agache I, Agusti A, Alonso A, et al. Integrated care pathways for airway diseases (AIRWAYS-ICPS). Eur Respir J. 2014;44(2):304-23.

5. Bousquet J, Dahl R, Khaltaev N. Global alliance against chronic respiratory diseases. Allergy. 2007;62(3):216-23.

6. Bourret R, Bousquet J, Mercier J, Camuzat T, Bedrook A, Demoly P, et al. MASK rhinitis, a single tool for integrated care pathways in allergic rhinitis. World Hosp Health Serv. 2015;51(3):36-9.

7. Bousquet J, Schunemann HJ, Fonseca J, Samolinski B, Bachert C, Canonica GW, et al. MACVIA-ARIA Sentinel Network for allergic rhinitis
(MASK-rhinitis): the new generation guideline implementation. Allergy. 2015;70(11):1372-92.

8. Bousquet J, Schunemann HJ, Hellings PW, Arnavielhe S, Bachert C, Bedbrook A, et al. MACVIA clinical decision algorithm in adolescents and adults with allergic rhinitis. J Allergy Clin Immunol. 2016;138(2):367-74. e2.

9. Hellings PW, Muraro A, Fokkens W, Mullol J, Bachert C, Canonica GW, et al. A common language to assess allergic rhinitis control: results from a survey conducted during EAACI 2013 Congress. Clin Transl Allergy. 2015;5:36.

10. Price D, Smith P, Hellings P, Papadopoulos N, Fokkens W, Muraro A, et al. Current controversies and challenges in allergic rhinitis management. Expert Rev Clin Immunol. 2015;11(11):1205-17.

11. Bousquet J, Farrell J, Crooks G, Hellings P, Bel EH, Bewick M, et al. Scaling up strategies of the chronic respiratory disease programme of the European Innovation Partnership on Active and Healthy Ageing (Action Plan B3: Area 5). Clin Transl Allergy. 2016;6:29.

12. Bousquet J, Anto JM, Berkouk K, Gergen P, Antunes JP, Auge P, et al. Developmental determinants in non-communicable chronic diseases and ageing. Thorax. 2015;70(6):595-7.

13. Samolinski B, Fronczak A, Kuna P, Akdis CA, Anto JM, Bialoszewski AZ, et al. Prevention and control of childhood asthma and allergy in the EU from the public health point of view: Polish Presidency of the European Union. Allergy. 2012;67(6):726-31.

14. Johansson SG, Bieber T, Dahl R, Friedmann PS, Lanier BQ, Lockey RF, et al. Revised nomenclature for allergy for global use: report of the Nomenclature Review Committee of the World Allergy Organization, October 2003. J Allergy Clin Immunol. 2004;113(5):832-6.

15. Bousquet J, Khaltaev N, Cruz AA, Denburg J, Fokkens WJ, Togias A, et al. Allergic rhinitis and its impact on asthma (ARIA) 2008 update (in collaboration with the World Health Organization, GA²LEN and AllerGen) Allergy. 2008;63(Suppl. 86):8-160.

16. Bousquet J, Khaltaev N. Global surveillance, prevention and control of chronic respiratory diseases. A comprehensive approach. In: Global alliance against chronic respiratory diseases. Geneva: World Health Organization; 2007. ISBN: 978-92-4-156346-8.

17. Bieber T. Atopic dermatitis. N Engl J Med. 2008;358(14):1483-94.

18. Pearce N, Pekkanen J, Beasley R. How much asthma is really attributable to atopy? Thorax. 1999;54(3):268-72.

19. Weinmayr G, Forastiere F, Weiland SK, Rzehak P, Abramidze T, AnnesiMaesano I, et al. International variation in prevalence of rhinitis and its relationship with sensitisation to perennial and seasonal allergens. Eur Respir J. 2008;32(5):1250-61.

20. Bousquet PJ, Leynaert B, Neukirch F, Sunyer J, Janson CM, Anto J, et al. Geographical distribution of atopic rhinitis in the European Community Respiratory Health Survey I. Allergy. 2008;63(10):1301-9.

21. Bousquet J, Fokkens W, Burney P, Durham SR, Bachert C, Akdis CA, et al. Important research questions in allergy and related diseases: nonallergic rhinitis: a GA²LEN paper. Allergy. 2008;63(7):842-53.

22. Gupta R, Sheikh A, Strachan DP, Anderson HR. Burden of allergic disease in the UK: secondary analyses of national databases. Clin Exp Allergy. 2004;34(4):520-6.

23. Anandan C, Gupta R, Simpson CR, Fischbacher C, Sheikh A. Epidemiology and disease burden from allergic disease in Scotland: analyses of national databases. J R Soc Med. 2009:102(10):431-42.

24. Bousquet J, Van Cauwenberge P, Khaltaev N. Allergic rhinitis and its impact on asthma. J Allergy Clin Immunol. 2001;108(5 Suppl.):S147-334.

25. Walker S, Khan-Wasti S, Fletcher M, Cullinan P, Harris J, Sheikh A. Seasonal allergic rhinitis is associated with a detrimental effect on examination performance in United Kingdom teenagers: case-control study. J Allergy Clin Immunol. 2007;120(2):381-7.

26. Bousquet J, Bachert C, Canonica GW, Casale TB, Cruz AA, Lockey RJ, et al. Unmet needs in severe chronic upper airway disease (SCUAD). J Allergy Clin Immunol. 2009;124(3):428-33.

27. Haahtela T, Valovirta E, Kauppi P, Tommila E, Saarinen K, von Hertzen L, et al. The Finnish allergy programme 2008-2018-scientific rationale and practical implementation. Asia Pac Allergy. 2012;2(4):275-9.

28. Bousquet J, Anto JM, Akdis M, Auffray C, Keil T, Momas I, et al. Paving the way of systems biology and precision medicine in allergic diseases: the MeDALL success story. Allergy. 2016;71(11):1513-25. 
29. Bousquet J, Anto JM, Wickman M, Keil T, Valenta R, Haahtela T, et al. Are allergic multimorbidities and IgE polysensitization associated with the persistence or re-occurrence of foetal type 2 signalling? The MeDALL hypothesis. Allergy. 2015;70(9):1062-78.

30. Hatzler L, Panetta V, Lau S, Wagner P, Bergmann RL, Illi S, et al. Molecular spreading and predictive value of preclinical IgE response to Phleum pratense in children with hay fever. J Allergy Clin Immunol. 2012;130(4):894-901 e5.

31. Asarnoj A, Hamsten C, Waden K, Lupinek C, Andersson N, Kull I, et al. Sensitization to cat and dog allergen molecules in childhood and prediction of symptoms of cat and dog allergy in adolescence: a BAMSE/ MeDALL study. J Allergy Clin Immunol. 2016;137(3):813-21.

32. Westman M, Lupinek C, Bousquet J, Andersson N, Pahr S, Baar A, et al. Early childhood IgE reactivity to pathogenesis-related class 10 proteins predicts allergic rhinitis in adolescence. J Allergy Clin Immunol. 2015;135(5):1199 e1-11-1206 e1-11.

33. Pinart M, Benet M, Annesi-Maesano I, von Berg A, Berdel D, Carlsen KC, et al. Comorbidity of eczema, rhinitis, and asthma in IgE-sensitised and non-IgE-sensitised children in MeDALL: a population-based cohort study. Lancet Respir Med. 2014;2(2):131-40.

34. Simpson A, Lazic N, Belgrave DC, Johnson P, Bishop C, Mills C, et al. Patterns of lgE responses to multiple allergen components and clinical symptoms at age 11 years. J Allergy Clin Immunol. 2015;136(5):1224-31.

35. Ballardini N, Bergstrom A, Wahlgren CF, van Hage M, Hallner E, Kull I, et al. IgE antibodies in relation to prevalence and multimorbidity of eczema, asthma, and rhinitis from birth to adolescence. Allergy. 2016;71(3):342-9.

36. Belgrave DC, Granell R, Simpson A, Guiver J, Bishop C, Buchan I, et al. Developmental profiles of eczema, wheeze, and rhinitis: two population-based birth cohort studies. PLoS Med. 2014;11(10):e1001748.

37. Melioli G, Bonifazi F, Bonini S, Maggi E, Mussap M, Passalacqua G, et al. The ImmunoCAP ISAC molecular allergology approach in adult multisensitized Italian patients with respiratory symptoms. Clin Biochem. 2011:44(12):1005-11.

38. Postma DS, Bush A, van den Berge M. Risk factors and early origins of chronic obstructive pulmonary disease. Lancet. 2015;385(9971):899-909.

39. Kotz D, Simpson CR, Viechtbauer W, van Schayck OC, Sheikh A. Development and validation of a model to predict the 10-year risk of general practitioner-recorded COPD. NPJ Prim Care Respir Med. 2014;24:14011.

40. Smith AM, Villareal M, Bernstein DI, Swikert DJ. Asthma in the elderly: risk factors and impact on physical function. Ann Allergy Asthma Immunol. 2012;108(5):305-10

41. Bellia V, Pedone C, Catalano F, Zito A, Davi E, Palange S, et al. Asthma in the elderly: mortality rate and associated risk factors for mortality. Chest. 2007;132(4):1175-82.

42. Moscato G, Pala G, Boillat MA, Folletti I, Gerth van Wijk R, Olgiati-Des Gouttes D, et al. EAACI position paper: prevention of work-related respiratory allergies among pre-apprentices or apprentices and young workers. Allergy. 2011;66(9):1164-73.

43. Svanes C, Sunyer J, Plana E, Dharmage S, Heinrich J, Jarvis D, et al. Early life origins of chronic obstructive pulmonary disease. Thorax. 2010;65(1):14-20.

44. Jarvis $D$, Burney P. ABC of allergies. The epidemiology of allergic disease. BMJ. 1998;316(7131):607-10.

45. Linneberg A. Changes in atopy over 25 years: allergy epidemic has spread to old age. BMJ. 2005;331(7512):352.

46. Law M, Morris JK, Wald N, Luczynska C, Burney P. Changes in atopy over a quarter of a century, based on cross sectional data at three time periods. BMJ. 2005;330(7501):1187-8

47. Cruz AA, Popov T, Pawankar R, Annesi-Maesano I, Fokkens W, Kemp J, et al. Common characteristics of upper and lower airways in rhinitis and asthma: ARIA update, in collaboration with GA²LEN. Allergy. 2007;62(Suppl 84):1-41

48. Song WJ, Sohn KH, Kang MG, Park HK, Kim MY, Kim SH, et al. Urban-rural differences in the prevalence of allergen sensitization and self-reported rhinitis in the elderly population. Ann Allergy Asthma Immunol. 2015;114(6):455-61.

49. Wuthrich B, Schmid-Grendelmeier P, Schindler C, Imboden M, Bircher A, Zemp E, et al. Prevalence of atopy and respiratory allergic diseases in the elderly SAPALDIA population. Int Arch Allergy Immunol. 2013;162(2):143-8.
50. Calderon MA, Gerth van Wijk R, Eichler I, Matricardi PM, Varga EM, Kopp MV, et al. Perspectives on allergen-specific immunotherapy in childhood: an EAACI position statement. Pediatr Allergy Immunol. 2012;23(4):300-6.

51. Calderon MA, Casale T, Cox L, Akdis CA, Burks AW, Nelson HS, et al. Allergen immunotherapy: a new semantic framework from the European Academy of Allergy and Clinical Immunology/American Academy of Allergy, Asthma and Immunology/PRACTALL consensus report. Allergy. 2013;68(7):825-8.

52. Dhami S, Nurmatov U, Agache I, Lau S, Muraro A, Jutel M, et al. Allergen immunotherapy for allergic asthma: protocol for a systematic review. Clin Transl Allergy. 2015;6:5.

53. Jutel M, Agache I, Bonini S, Burks AW, Calderon M, Canonica W, et al. International consensus on allergen immunotherapy II: mechanisms, standardization, and pharmacoeconomics. J Allergy Clin Immunol. 2016;137(2):358-68.

54. Haahtela T, von Hertzen L, Makela M, Hannuksela M. Finnish allergy programme 2008-2018 - time to act and change the course. Allergy. 2008;63(6):634-45.

55. Didier A, Malling HJ, Worm M, Horak F, Jager S, Montagut A, et al. Optimal dose, efficacy, and safety of once-daily sublingual immunotherapy with a 5-grass pollen tablet for seasonal allergic rhinitis. J Allergy Clin Immunol. 2007;120(6):1338-45.

56. Virchow JC, Backer V, Kuna P, Prieto L, Nolte H, Villesen HH, et al. Efficacy of a house dust mite sublingual allergen immunotherapy tablet in adults with allergic asthma: a randomized clinical trial. JAMA. 2016;315(16):1715-25.

57. Price D, Scadding G, Ryan D, Bachert C, Canonica GW, Mullol J, et al. The hidden burden of adult allergic rhinitis: UK healthcare resource utilisation survey. Clin Transl Allergy. 2015;5:39

58. Hellings PW, Fokkens WJ, Akdis C, Bachert C, Cingi C, Dietz de Loos D, et al. Uncontrolled allergic rhinitis and chronic rhinosinusitis: where do we stand today? Allergy. 2013;68(1):1-7.

59. Durham SR, Emminger W, Kapp A, de Monchy JG, Rak S, Scadding GK, et al. SQ-standardized sublingual grass immunotherapy: confirmation of disease modification 2 years after 3 years of treatment in a randomized trial. J Allergy Clin Immunol. 2012;129(3):717-25.e5.

60. Didier A, Worm M, Horak F, Sussman G, de Beaumont O, Le Gall M, et al. Sustained 3-year efficacy of pre- and coseasonal 5-grass-pollen sublingual immunotherapy tablets in patients with grass pollen-induced rhinoconjunctivitis. J Allergy Clin Immunol. 2011;128(3):559-66.

61. Bousquet J. Sublingual immunotherapy: from proven prevention to putative rapid relief of allergic symptoms. Allergy. 2005;60(1):1-3.

62. Shamji MH, Durham SR. Mechanisms of immunotherapy to aeroallergens. Clin Exp Allergy. 2011;41(9):1235-46.

63. Akdis CA, Akdis M. Mechanisms of immune tolerance to allergens: role of IL-10 and Tregs. J Clin Invest. 2014;124(11):4678-80.

64. Bousquet J, Maasch H, Martinot B, Hejjaoui A, Wahl R, Michel FB. Double-blind, placebo-controlled immunotherapy with mixed grass-pollen allergoids. II. Comparison between parameters assessing the efficacy of immunotherapy. J Allergy Clin Immunol. 1988;82(3 Pt 1):439-46.

65. James LK, Bowen H, Calvert RA, Dodev TS, Shamji MH, Beavil AJ, et al. Allergen specificity of lgG(4)-expressing $B$ cells in patients with grass pollen allergy undergoing immunotherapy. J Allergy Clin Immunol. 2012;130(3):663-70.

66. Akdis CA, Akdis M. Mechanisms of allergen-specific immunotherapy and immune tolerance to allergens. World Allergy Organ J. 2015;8(1):17.

67. Radulovic S, Wilson D, Calderon M, Durham S. Systematic reviews of sublingual immunotherapy (SLIT). Allergy. 2011;66(6):740-52.

68. Calderon MA, Penagos M, Sheikh A, Canonica GW, Durham SR. Sublingual immunotherapy for allergic conjunctivitis: Cochrane systematic review and meta-analysis. Clin Exp Allergy. 2011;41(9):1263-72.

69. Burks AW, Calderon MA, Casale T, Cox L, Demoly P, Jutel M, et al. Update on allergy immunotherapy: American Academy of Allergy, Asthma \& Immunology/European Academy of Allergy and Clinical Immunology/ PRACTALL consensus report. J Allergy Clin Immunol. 2013;131(5):1288 e3-1296 e3.

70. Lin SY, Erekosima N, Kim JM, Ramanathan M, Suarez-Cuervo C, Chelladurai $Y$, et al. Sublingual immunotherapy for the treatment of allergic rhinoconjunctivitis and asthma: a systematic review. JAMA. 2013;309(12):1278-88. 
71. Pfaar O, Bachert C, Bufe A, Buhl R, Ebner C, Eng P, et al. Guideline on allergen-specific immunotherapy in lgE-mediated allergic diseases: S2k guideline of the German Society for Allergology and Clinical Immunology (DGAKI), the Society for Pediatric Allergy and Environmental Medicine (GPA), the Medical Association of German Allergologists (AeDA), the Austrian Society for Allergy and Immunology (OGAI), the Swiss Society for Allergy and Immunology (SGAI), the German Society of Dermatology (DDG), the German Society of Oto- Rhino-Laryngology, Head and Neck Surgery (DGHNO-KHC), the German Society of Pediatrics and Adolescent Medicine (DGKJ), the Society for Pediatric Pneumology (GPP), the German Respiratory Society (DGP), the German Association of ENT Surgeons (BV-HNO), the Professional Federation of Paediatricians and Youth Doctors $(B V K J)$, the Federal Association of Pulmonologists (BDP) and the German Dermatologists Association (BVDD). Allergo J Int. 2014;23(8):282-319.

72. Di Bona D, Plaia A, Leto-Barone MS, La Piana S, Di Lorenzo G. Efficacy of grass pollen allergen sublingual immunotherapy tablets for seasonal allergic rhinoconjunctivitis: a systematic review and meta-analysis. JAMA Intern Med. 2015;175(8):1301-9.

73. Canonica GW, Cox L, Pawankar R, Baena-Cagnani CE, Blaiss M, Bonini S, et al. Sublingual immunotherapy: World Allergy Organization position paper 2013 update. World Allergy Organ J. 2014;7(1):6.

74. Jutel M, Agache I, Bonini S, Burks AW, Calderon M, Canonica W, et al. International consensus on allergy immunotherapy. J Allergy Clin Immunol. 2015;136(3):556-68.

75. Marogna M, Bruno M, Massolo A, Falagiani P. Long-lasting effects of sublingual immunotherapy for house dust mites in allergic rhinitis with bronchial hyperreactivity: a long-term (13-year) retrospective study in real life. Int Arch Allergy Immunol. 2007;142(1):70-8.

76. Jacobsen L, Niggemann B, Dreborg S, Ferdousi HA, Halken S, Host $A$, et al. Specific immunotherapy has long-term preventive effect of seasonal and perennial asthma: 10-year follow-up on the PAT study. Allergy. 2007;62(8):943-8.

77. Moller C, Dreborg S, Ferdousi HA, Halken S, Host A, Jacobsen L, et al. Pollen immunotherapy reduces the development of asthma in children with seasonal rhinoconjunctivitis (the PAT-study). J Allergy Clin Immunol. 2002;109(2):251-6.

78. Valovirta E, Berstad AK, de Blic J, Bufe A, Eng P, Halken S, et al. Design and recruitment for the GAP trial, investigating the preventive effect on asthma development of an SQ-standardized grass allergy immunotherapy tablet in children with grass pollen-induced allergic rhinoconjunctivitis. Clin Ther. 2011;33(10):1537-46.

79. Hankin CS, Cox L. Allergy immunotherapy: what is the evidence for cost saving? Curr Opin Allergy Clin Immunol. 2014;14(4):363-70.

80. Meadows A, Kaambwa B, Novielli N, Huissoon A, Fry-Smith A, Meads C, et al. A systematic review and economic evaluation of subcutaneous and sublingual allergen immunotherapy in adults and children with seasonal allergic rhinitis. Health Technol Assess. 2013;17(27):vi, xi-xiv, $1-322$.

81. Holt PG, Strickland D, Bosco A, Belgrave D, Hales B, Simpson A, et al. Distinguishing benign from pathologic $\mathrm{TH} 2$ immunity in atopic children. J Allergy Clin Immunol. 2016;137(2):379-87.

82. Holt PG, Sly PD, Sampson HA, Robinson P, Loh R, Lowenstein $\mathrm{H}$, et al. Prophylactic use of sublingual allergen immunotherapy in high-risk children: a pilot study. J Allergy Clin Immunol. 2013;132(4):991 e1-993 e1.

83. Zolkipli Z, Roberts G, Cornelius V, Clayton B, Pearson S, Michaelis L, et al. Randomized controlled trial of primary prevention of atopy using house dust mite allergen oral immunotherapy in early childhood. J Allergy Clin Immunol. 2015;136(6):1541-7.

84. Glovsky MM, Ghekiere L, Rejzek E. Effect of maternal immunotherapy on immediate skin test reactivity, specific rye I lgG and IgE antibody, and total lgE of the children. Ann Allergy. 1991;67(1):21-4.

85. Matricardi PM. Allergen-specific immunoprophylaxis: toward secondary prevention of allergic rhinitis? Pediatr Allergy Immunol. 2014;25(1):15-8.

86. Ranciere F, Nikasinovic L, Bousquet J, Momas I. Onset and persistence of respiratory/allergic symptoms in preschoolers: new insights from the PARIS birth cohort. Allergy. 2013;68(9):1158-67.

87. Garcia-Aymerich J, Benet M, Saeys Y, Pinart M, Basagana X, Smit HA, et al. Phenotyping asthma, rhinitis and eczema in MeDALL population-based birth cohorts: an allergic comorbidity cluster. Allergy. 2015;70(8):973-84.
88. Amat F, Saint-Pierre P, Bourrat E, Nemni A, Couderc R, Boutmy-Deslandes $\mathrm{E}$, et al. Early-onset atopic dermatitis in children: which are the phenotypes at risk of asthma? Results from the ORCA cohort. PLoS One. 2015;10(6):e0131369.

89. Just J, Deslandes-Boutmy E, Amat F, Desseaux K, Nemni A, Bourrat E, et al. Natural history of allergic sensitization in infants with early-onset atopic dermatitis: results from ORCA study. Pediatr Allergy Immunol. 2014;25(7):668-73.

90. Pfaar O, Demoly P, Gerth van Wijk R, Bonini S, Bousquet J, Canonica GW et al. Recommendations for the standardization of clinical outcomes used in allergen immunotherapy trials for allergic rhinoconjunctivitis: an EAACI position paper. Allergy. 2014;69(7):854-67.

91. Burnay E, Cruz-Correia R, Jacinto T, Sousa AS, Fonseca J. Challenges of a mobile application for asthma and allergic rhinitis patient enablementinterface and synchronization. Telemed J e-Health. 2013;19(1):13-8.

92. Morais-Almeida M, Pite H, Pereira AM, Todo-Bom A, Nunes C, Bousquet $J$, et al. Prevalence and classification of rhinitis in the elderly: a nationwide survey in Portugal. Allergy. 2013;68(9):1150-7.

93. Berger W, Meltzer EO, Amar N, Fox AT, Just J, Muraro A, et al. Efficacy of MP-AzeFlu in children with seasonal allergic rhinitis: importance of paediatric symptom assessment. Pediatr Allergy Immunol. 2016;27(2):126-33.

94. Wahn U. Assessing rhinitis symptoms in children-a need for action. Pediatr Allergy Immunol. 2016;27(2):114-6.

95. Soyiri IN, Nwaru BI, Sheikh A. Patient-reported outcome measures for allergy and asthma in children. Pediatr Allergy Immunol. 2016. doi:10.1111/pai.12603.

96. Klimek L, Bachert C, Mosges R, Munzel U, Price D, Virchow JC, et al. Effectiveness of MP29-02 for the treatment of allergic rhinitis in real-life: results from a noninterventional study. Allergy Asthma Proc. 2015;36(1):40-7.

97. Worth A, Hammersley V, Knibb R, Flokstra-de-Blok B, DunnGalvin A, Walker S, et al. Patient-reported outcome measures for asthma: a systematic review. NPJ Prim Care Respir Med. 2014;24:14020.

98. Canonica GW, Bachert C, Hellings P, Ryan D, Valovirta E, Wickman M, et al. Allergen immunotherapy (AIT): a prototype of precision medicine. World Allergy Organ J. 2015;8(1):31.

99. Fleming L, Murray C, Bansal AT, Hashimoto S, Bisgaard H, Bush $A$, et al. The burden of severe asthma in childhood and adolescence: results from the paediatric U-BIOPRED cohorts. Eur Respir J. 2015;46(5):1322-33.

100. Loza MJ, Adcock I, Auffray C, Chung KF, Djukanovic R, Sterk PJ, et al. Longitudinally stable, clinically defined clusters of patients with asthma independently identified in the ADEPT and U-BIOPRED asthma studies. Ann Am Thorac Soc. 2016;13(Suppl. 1):S102-3.

101. Shaw DE, Sousa AR, Fowler SJ, Fleming LJ, Roberts G, Corfield J, et al. Clinical and inflammatory characteristics of the European U-BIOPRED adult severe asthma cohort. Eur Respir J. 2015:46(5):1308-21.

102. Nolte M, Barber D, Maloney J, Li Z, Kaur A, Galan A, et al. Timothy specific lgE levels are associated with efficacy and safety of timothy grass sublingual immunotherapy tablet. Ann Allergy Asthma Immunol. 2015;115(6):509-15.e2.

103. Hoffmann HJ, Santos AF, Mayorga C, Nopp A, Eberlein B, Ferrer M, et al. The clinical utility of basophil activation testing in diagnosis and monitoring of allergic disease. Allergy. 2015;70(11):1393-405.

104. Gueguen C, Bouley J, Moussu H, Luce S, Duchateau M, Chamot-Rooke $J$, et al. Changes in markers associated with dendritic cells driving the differentiation of either $\mathrm{TH} 2$ cells or regulatory T cells correlate with clinical benefit during allergen immunotherapy. J Allergy Clin Immunol. 2016;137(2):545-58.

105. Bousquet J, Jorgensen C, Dauzat M, Cesario A, Camuzat T, Bourret R, et al. Systems medicine approaches for the definition of complex phenotypes in chronic diseases and ageing. From concept to implementation and policies. Curr Pharm Des. 2014;20(38):5928-44.

106. Tripodi S, Frediani T, Lucarelli S, Macri F, Pingitore G, Di Rienzo BusincoA, et al. Molecular profiles of IgE to Phleum pratense in children with grass pollen allergy: implications for specific immunotherapy. J Allergy Clin Immunol. 2012;129(3):834-9.e8.

107. Custovic A, Sonntag HJ, Buchan IE, Belgrave D, Simpson A, Prosperi MC. Evolution pathways of $\mathrm{IgE}$ responses to grass and mite allergens throughout childhood. J Allergy Clin Immunol. 2015;136(6):1645-52.e1-8. 
108. Stringari G, Tripodi S, Caffarelli C, Dondi A, Asero R, Di Rienzo BusincoA, et al. The effect of component-resolved diagnosis on specific immunotherapy prescription in children with hay fever. J Allergy Clin Immunol. 2014;134(1):75-81.

109. Bousquet J, Braquemond P, Feinberg J, Guerin B, Maasch H, Michel FB. Specific lgE response before and after rush immunotherapy with a standardized allergen or allergoid in grass pollen allergy. Ann Allergy. 1986;56(6):456-9.

110. Kuitunen M, Englund H, Remes S, Moverare R, Pelkonen A, Borres MP, et al. High IgE levels to alpha-lactalbumin, beta-lactoglobulin and casein predict less successful cow's milk oral immunotherapy. Allergy. 2015;70(8):955-62.

111. Oykhman P, Kim HL, Ellis AK. Allergen immunotherapy in pregnancy. Allergy Asthma Clin Immunol. 2015;11:31.

112. Tam H, Calderon MA, Manikam L, Nankervis H, Garcia Nunez I, Williams $\mathrm{HC}$, et al. Specific allergen immunotherapy for the treatment of atopic eczema. Cochrane Database Syst Rev. 2016;2:CD008774.

113. Khinchi MS, Poulsen LK, Carat F, Andre C, Hansen AB, Malling HJ. Clinical efficacy of sublingual and subcutaneous birch pollen allergen-specific immunotherapy: a randomized, placebo-controlled, double-blind, double-dummy study. Allergy. 2004;59(1):45-53.

114. Larenas Linnemann DE, Blaiss MS. Selection of patients for sublingual versus subcutaneous immunotherapy. Immunotherapy. 2014;6(7):871-84.

115. Bousquet J, Schunemann HJ, Bousquet PJ, Bachert C, Canonica GW, Casale TB, et al. How to design and evaluate randomized controlled trials in immunotherapy for allergic rhinitis: an ARIA-GA ${ }^{2}$ LEN statement. Allergy. 2011;66(6):765-74.

116. Bousquet PJ, Brozek J, Bachert C, Bieber T, Bonini S, Burney P, et al. The CONSORT statement checklist in allergen-specific immunotherapy: a GA²LEN paper. Allergy. 2009;64(12):1737-45.

117. Bachert C, Larche M, Bonini S, Canonica GW, Kundig T, Larenas-Linnemann $D$, et al. Allergen immunotherapy on the way to product-based evaluation — a WAO statement. World Allergy Organ J. 2015;8(1):29.
118. Calderon MA, Eichel A, Makatsori M, Pfaar O. Comparability of subcutaneous and sublingual immunotherapy outcomes in allergic rhinitis clinical trials. Curr Opin Allergy Clin Immunol. 2012;12(3):249-56.

119. Hankin CS, Cox L, Bronstone A, Wang Z. Allergy immunotherapy: reduced health care costs in adults and children with allergic rhinitis. J Allergy Clin Immunol. 2013;131(4):1084-91.

120. Jutel M, Jaeger L, Suck R, Meyer H, Fiebig H, Cromwell O. Allergen-specific immunotherapy with recombinant grass pollen allergens. J Allergy Clin Immunol. 2005:116(3):608-13.

121. Pauli G, Larsen TH, Rak S, Horak F, Pastorello E, Valenta R, et al. Efficacy of recombinant birch pollen vaccine for the treatment of birch-allergic rhinoconjunctivitis. J Allergy Clin Immunol. 2008;122(5):951-60.

122. Kopp MV, Hamelmann E, Zielen S, Kamin W, Bergmann KC, Sieder C, et al. Combination of omalizumab and specific immunotherapy is superior to immunotherapy in patients with seasonal allergic rhinoconjunctivitis and co-morbid seasonal allergic asthma. Clin Exp Allergy. 2009;39(2):271-9.

123. Casale TB, Busse WW, Kline JN, Ballas ZK, Moss MH, Townley RG, et al. Omalizumab pretreatment decreases acute reactions after rush immunotherapy for ragweed-induced seasonal allergic rhinitis. J Allergy Clin Immunol. 2006;117(1):134-40.

124. Massanari M, Nelson H, Casale T, Busse W, Kianifard F, Geba GP, et al. Effect of pretreatment with omalizumab on the tolerability of specific immunotherapy in allergic asthma. J Allergy Clin Immunol. 2010;125(2):383-9.

125. Chaker AM, Shamji MH, Dumitru FA, Calderon MA, Scadding GW, Makatsori $\mathrm{M}$, et al. Short-term subcutaneous grass pollen immunotherapy under the umbrella of anti-IL-4: a randomized controlled trial. J Allergy Clin Immunol. 2016;137(2):452-61.e9.

126. Matui P, Wyatt JC, Pinnock H, Sheikh A, McLean S. Computer decision support systems for asthma: a systematic review. NPJ Prim Care Respir Med. 2014;24:14005.

\section{Submit your next manuscript to BioMed Central and we will help you at every step:}

- We accept pre-submission inquiries

- Our selector tool helps you to find the most relevant journal

- We provide round the clock customer support

- Convenient online submission

- Thorough peer review

- Inclusion in PubMed and all major indexing services

- Maximum visibility for your research

Submit your manuscript at www.biomedcentral.com/submit
O Biomed Central 